Check for updates

Cite this: Chem. Sci., 2019, 10, 6672

๑ All publication charges for this article have been paid for by the Royal Society of Chemistry

Received 26th April 2019

Accepted 24th May 2019

DOI: $10.1039 / c 9 s c 02087 j$

rsc.li/chemical-science

\section{Snapshots of magnesium-centred diborane heterolysis by an outer sphere $\mathrm{S}_{\mathrm{N}} 2$ process $\dagger$}

\author{
Anne-Frédérique Pécharman, Michael S. Hill, (D) * Grace McMullon, \\ Claire L. McMullin* and Mary F. Mahon
}

Reactions of the $\beta$-diketiminato magnesium diboranate derivative, [(BDI)Mg\{pinB( $n$-Bu)Bpin\}] $(\mathrm{BDI}=\mathrm{HC}$ $\left.\{(\mathrm{Me}) \mathrm{CNDipp}\}_{2} ; \operatorname{Dipp}=2,6-\mathrm{i}-\mathrm{Pr}_{2} \mathrm{C}_{6} \mathrm{H}_{3}\right)$, with $\mathrm{N}, \mathrm{N}^{\prime}$-dialkyl and $\mathrm{N}, \mathrm{N}^{\prime}$-diaryl carbodiimides provided the corresponding $\mathrm{C}$-borylated magnesium borylamidinates. This reactivity occurs with the displacement of $n$-BuBpin and with the apparent addition of a nucleophilic \{Bpin\} anion to the electrophilic unsaturated carbodiimide carbon centres. In contrast, while analogous reactions of [(BDI)Mg\{pinB( $n-B u) B p i n\}]$ with $N$-alkyl or $N$-aryl aldimines and ketimines also resulted in facile displacement of $n$-BuBpin, they provided the organomagnesium products of $\{$ Bpin\} addition to the imine nitrogen atom rather than the more electrophilic trigonal imine carbon. Computational assessment by density functional theory (DFT) indicated that, although the energetic differences are marginal, the organomagnesium products may be considered as the kinetic outcome of these reactions with respect to the generation of alternative amidomagnesium regioisomers. This latter deduction was borne out by the thermally-induced conversion of two such organomagnesium species to their C-borylated amidomagnesium isomers, both of which occur with negligible entropies of activation indicative of purely intramolecular processes. Detailed analysis by DFT of the reaction of [(BDI)Mg\{pinB( $n-\mathrm{Bu}) \mathrm{Bpin}\}]$ with $\mathrm{PhN}=\mathrm{CHPh}$ indicated that $\mathrm{B}-\mathrm{N}$ bond formation is initiated by attack of the imine nitrogen at the three-coordinate boron atom of the diboranate anion rather than the more crowded magnesium centre. Consistent with an effectively spontaneous reaction, the resultant cleavage of the $\mathrm{B}-\mathrm{B}$ bond of the diboranate unit is accomplished via the traversal of two very modest barriers of only 8.3 and $6.7 \mathrm{kcal} \mathrm{mol}^{-1}$. This analysis was also supportive of a subsequent intramolecular $\mathrm{B}-\mathrm{N}$ to $\mathrm{B}-\mathrm{C}$ isomerisation process. Of greater general significance, however, the addition of the BBpin $^{-}$anion to the reducible aldimine is best rationalised as a consequence of the electrophilic character of this three-coordinate boron centre rather than any intrinsic nucleophilicity associated with the B-B bond of the $[\mathrm{pinBB}(n-\mathrm{Bu}) \text { pin] }]^{-}$anion.

\section{Introduction}

Although many boron-heteroatom (e.g. C, N, O) bonds may be generated by the reaction of an appropriate heteroelement nucleophile and a boron electrophile, the relative dearth of complementary anionic or nucleophilic boron species remains as something of a bottleneck in main group element synthesis. The viability of model lithioboranes was discussed by Schleyer and co-workers as long ago as 1995, their calculations suggesting that singlet boryl derivatives, $\mathrm{X}_{2} \mathrm{~B}-\mathrm{Li}$, may be accessible

Department of Chemistry, University of Bath, Claverton Down, Bath, BA2 7AY, UK. E-mail:msh27@bath.ac.uk; cm2025@bath.ac.uk

$\dagger$ Electronic supplementary information (ESI) available: Experimental details, characterisation data, X-ray crystallographic information, computational details, and tables of Cartesian coordinates (PDF). Crystallographic (CIF) data for compounds $11,14,15_{\mathrm{BN}}, 16_{\mathrm{BN}}, 17_{\mathrm{BN}}, 18_{\mathrm{BN}}, 17_{\mathrm{BC}}$ and $18_{\mathrm{Ph}}$ are available from the Cambridge Structural Database as CCDC 1910885-1910892. For ESI and crystallographic data in CIF or other electronic format see DOI: $10.1039 / \mathrm{c} 9 \mathrm{sc} 02087 \mathrm{j}$ through the introduction of stabilising electronegative $\mathrm{X}$ substituents (e.g. F, O, N). ${ }^{1}$ This supposition was ultimately borne out by Yamashita and Nozaki's pivotal isolation of the lithium diaminoboryl, compound $\mathbf{1},{ }^{2-6}$ which has been shown to act as a competent nucleophile towards a wide range of electrophilic organic and inorganic reagents. ${ }^{7-15}$<smiles>CC(C)(C)OB1N([O+])C=CN1[O+]</smiles>

(1)

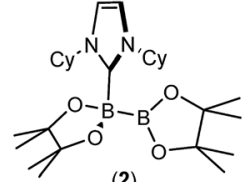

(2)

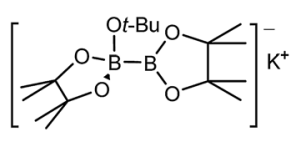

(3)
Dipp $=2,6-i-\mathrm{Pr}_{2} \mathrm{C}_{6} \mathrm{H}_{3}$

While the synthesis of $\mathbf{1}$ instigated the development of a plethora of related anionic and neutral nucleophilic boron species, access to a vast majority of these derivatives, like $\mathbf{1}$ itself, requires the synthetically inconvenient reaction of a haloborane precursor with a potent alkali metal reductant. ${ }^{16-34}$ The realisation that the desymmetrisation of commercially available 
diboranes, e.g. the bis(pinacolato)diborane $\left(\mathrm{B}_{2} \mathrm{pin}_{2}\right)$ adducts, 2 and 3, can provide surrogates for boryl anions is, thus, an important advance toward practicality that has prompted significant experimental and theoretical attention. ${ }^{35-52}$ Fernandez, Bo and co-workers, for example, performed density functional theory (DFT) calculations on the 'transition metal-free' diboration of non-activated alkenes and the hydroboration of enone substrates. ${ }^{\mathbf{3 9 , 4 4 , 5 3}}$ Their proposed mechanism, leading to the hydroboration of methyl acrylate (Scheme 1), is predicated on an induced polarisation across the B-B bond such that one of the boron centres gains a strong nucleophilic character. A significant positive charge of +0.98 was calculated at the fourcoordinate boron atom of the anionic Lewis base adduct between $\mathrm{B}_{2}$ pin $_{2}$ and $\mathrm{MeO}^{-}$(shown as the intermediate anion $\mathbf{A}$ in Scheme 1). Although a calculated charge of +0.56 also inferred that the remaining $\mathrm{sp}^{2}$ boron atom should be significantly electrophilic, the behaviour of $\mathbf{A}$ as a source of the [Bpin] $]^{-}$ nucleophile was rationalised as a consequence of the resultant charge separation $(\Delta q=0.42)$ across the $\mathrm{B}\left(\mathrm{sp}^{2}\right)-\mathrm{B}\left(\mathrm{sp}^{3}\right)$ bond. On this basis, nucleophilic addition of the $\{$ Bpin $\}$ moiety was mooted to take place by the assembly of a transition state via (TS $_{\mathbf{A B}}$, Scheme 1) involving overlap of the polarised B-B $\sigma$ bond and the $\pi^{*}$ (LUMO) of the alkene. The neutral pinBOMe byproduct is then released and formation of the $\beta$-borylation product $(\mathbf{C})$ is achieved through protonation of the resultant anionic intermediate (B) by methanol, which is typically added in a five-fold excess to act as a source of methoxide anion. The explicit generation of any boryl anion, therefore, has neither been experimentally observed nor theoretically implicated during this nucleophilic borylation chemistry. Notably, the initial computational treatment of Bo and Fernandez and a more recent theoretical analysis of this 'transition metal-free' reactivity also disregard any explicit role for the alkali metal



Scheme 1 DFT calculated (BP86\\M06) reaction pathway proposed by Bo and Fernandez for the base initiated conjugate addition/ hydroboration of methyl acrylate by $\mathrm{B}_{2} \mathrm{pin}_{2}{ }^{53}$ cation, ${ }^{53,54}$ despite its introduction, most commonly as $\mathrm{Cs}_{2} \mathrm{CO}_{3}$ or $\mathrm{NaO} t-\mathrm{Bu}$, as a necessary component of the catalytic mixture.

We have recently reported that compounds such as 5, comprising $\mathrm{B}\left(\mathrm{sp}^{2}\right)-\mathrm{B}\left(\mathrm{sp}^{3}\right)$ diboranate anions reminiscent of $\mathbf{A}$, are easily synthesised by reactions of the $\beta$-diketiminato $n$ butylmagnesium derivative [(BDI)Mgn-Bu], 4, $(\mathrm{BDI}=\mathrm{HC}\{(\mathrm{Me})$ CNDipp $\}_{2}$; Dipp $=2,6-i-\operatorname{Pr}_{2} \mathrm{C}_{6} \mathrm{H}_{3}$ ) with the relevant diborane (Scheme 2). Treatment of the resultant derivatives with 4dimethylaminopyridine (DMAP) induces the heterolytic elimination of $n$-butyl boron pinacolate ester and the generation of terminal magnesium boryl derivatives such as compound $6 .^{55,56}$ In our initial account of this chemistry we reported that compound 6 reacts as an unambiguous boryl nucleophile with a range of organic electrophiles including benzophenone and $N, N^{\prime}$-di-iso-propylcarbodiimide to provide the $\mathrm{B}-\mathrm{C}$ bonded borylalkoxide and borylamidinate derivatives, compounds 7 and 8. By analogy to the well-established reactivity of $\mathrm{Mg}-\mathrm{H}$ or $\mathrm{Mg}-\mathrm{C}$ bonds with similar heterocumulene electrophiles, ${ }^{\text {57-60 }}$ these reactions are readily rationalised to result from insertion reactions of the $\mathrm{C}=\mathrm{O}$ and $\mathrm{C}=\mathrm{N}$ bonded substrates into the polarised $\mathrm{Mg}-\mathrm{B}$ bond of $\mathbf{6}$. In subsequent research we have observed that the diboranate (5) itself is also an apparent source of the [Bpin] nucleophile. ${ }^{61-63}$ Of relevance to the current study, addition of 5 to organic isocyanates provided the anticipated Cboryl amidates (e.g. 9) whereas reactions of diaryl ketones such as benzophenone resulted in aryl dearomatisation and the enolate reaction product $(\mathbf{1 0})$ rather than thermodynamically preferred C-borylation of the electrophilic $\mathrm{C}=\mathrm{O}$ unit. ${ }^{62}$ In this contribution, we extend our study of the reactivity of 5 to representative carbodiimide and imine substrates. Although isoelectronic with the previously described isocyanate and carbonyl-containing small molecules, we speculated that the additional $N$-substitution of these substrates would enable greater kinetic discrimination and, in so doing, provide an opportunity for more direct experimental investigation of the nature of the $\mathrm{B}-\mathrm{B}$ bond breaking process and the origin of the nucleophilic behaviour of $\mathrm{B}\left(\mathrm{sp}^{2}\right)-\mathrm{B}\left(\mathrm{sp}^{3}\right)$ bonded species.

\section{Results and discussion}

An initial reaction was performed in toluene between equimolar quantities of compound $\mathbf{5}$ and $N, N^{\prime}$-di-tert-butylcarbodiimide. Heating to $80^{\circ} \mathrm{C}$ induced complete consumption of the starting materials through the elimination of $n$-BuBpin $\left[\delta\left({ }^{11} \mathrm{~B}\right)=34.3\right.$ $\mathrm{ppm}]$ and the formation of a single new symmetrical $\beta$-diketiminate species (11). This latter compound was most clearly characterised by the appearance of new singlet resonances at $\delta 1.10$ and $1.24 \mathrm{ppm}$ in the resultant ${ }^{1} \mathrm{H}$ NMR spectrum. These signals integrated with respective intensities of $12 \mathrm{H}$ and $18 \mathrm{H}$ relative to the $1 \mathrm{H}$ BDI methine proton observed at $4.89 \mathrm{ppm}$ allowing the identification of compound $\mathbf{1 1}$ as a magnesium Cborylamidinate resulting from formal boryl anion addition to the sp-hybridised carbodiimide carbon atom. Although the end result of this process is analogous to the synthesis of compound 8 (Scheme 2), B-C bond formation is enabled without the observable generation of a magnesium boryl and it is apparent that addition of the carbodiimide initiates the necessary 


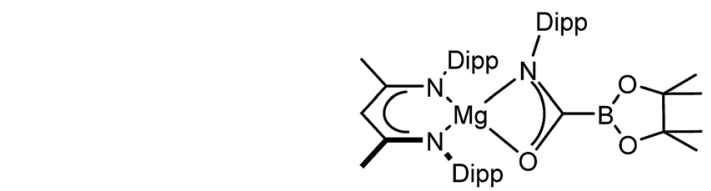

(9)

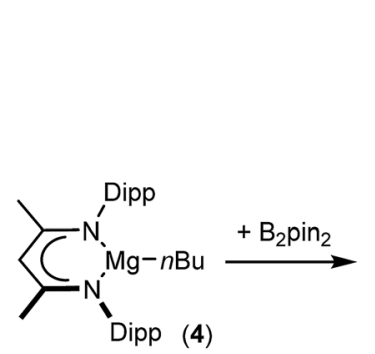

Dipp $=2,6-i-\mathrm{Pr}_{2} \mathrm{C}_{6} \mathrm{H}_{3}$

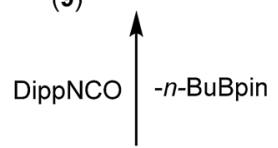

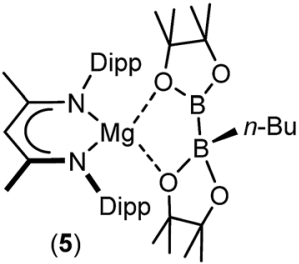<smiles>CCCCCCCCCCCCCCCCCC(=O)c1ccccc1</smiles>

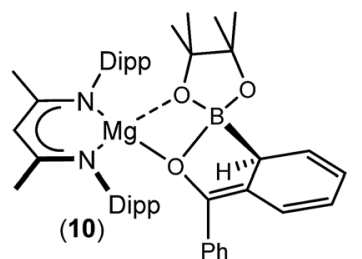

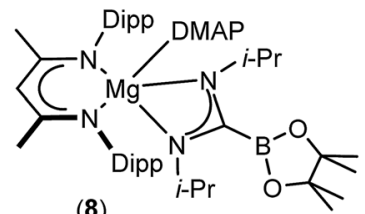

(8)

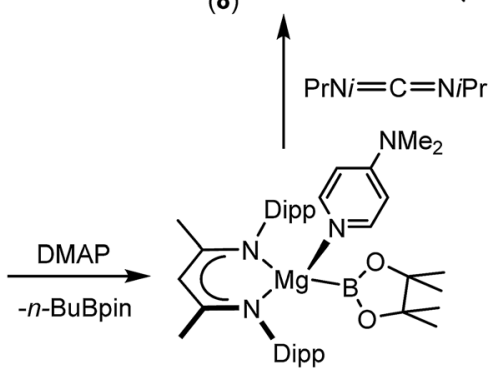

(6)

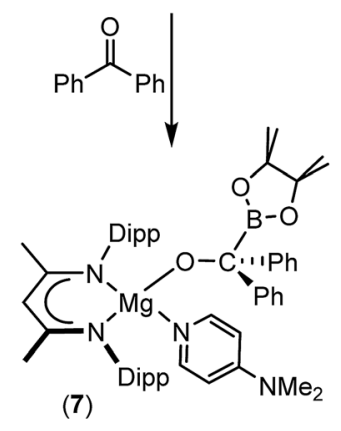

Scheme 2 Synthesis and previously reported reactivity of compounds 5 and 6 .

heterolysis of the $\mathrm{B}\left(\mathrm{sp}^{2}\right)-\mathrm{B}\left(\mathrm{sp}^{3}\right)$ bond of compound 5 . The identity of compound $\mathbf{1 1}$ was confirmed by removal of the reaction solvent and crystallisation of the resultant solid from hexane at $-35{ }^{\circ} \mathrm{C}$. This procedure yielded single crystals suitable for X-ray diffraction analysis, the results of which are displayed in Fig. 1a.

The structure of compound $\mathbf{1 1}$ comprises a C-borylamidinate ligand formed by the delivery of a $[\mathrm{pinB}]^{-}$anion to the (a)

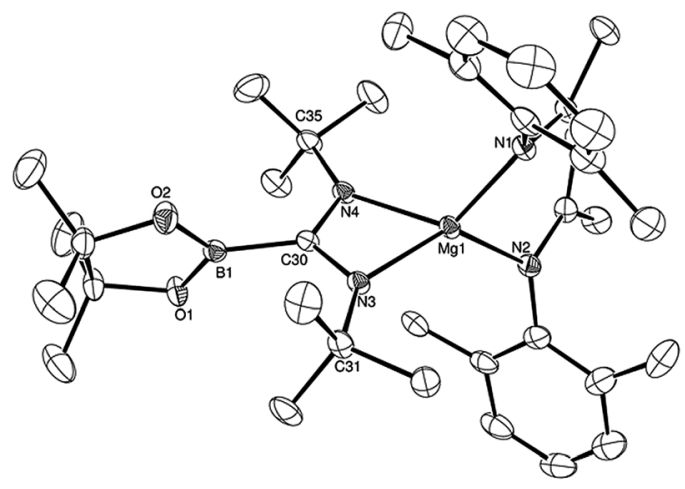

(b)

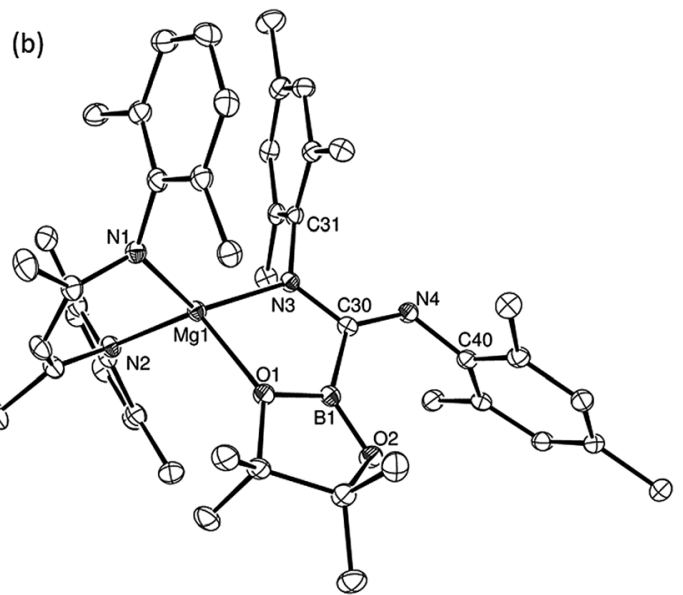

Fig. 1 ORTEP representations (25\% probability ellipsoids) of (a) compound 11 and (b) compound 14. Hydrogen atoms and iso-propyl methyl carbon atoms are removed for clarity. Selected bond lengths ( $\AA$ ) and angles ( ${ }^{\circ}$ ): (11) Mg1-N1 2.0394(18), Mg1-N2 2.0384(19), Mg1-N3 2.0193(17), Mg1-N4 2.0638(18), N3-C30 1.344(3), N4-C30 1.338(3), C30-B1 1.593(3), N2-Mg1-N1 94.72(8), N2-Mg1-N4 122.70(8), N1-Mg1-N4 119.70(8), N3-Mg1-N1 123.37(8), N3-Mg1-N2 131.68(8), N3-C30-Mg1 55.02(10), N3-C30-B1 123.89(17), N4-C30-Mg1 56.91(10), N4-C30N3 111.93(17), N4-C30-B1 124.17(18), B1-C30-Mg1 178.91(14); (14) N1-Mg1 2.043(2), N2-Mg1 2.053(2), N3-Mg1 2.005(2), O1-Mg1 2.1043(17), C30-B1 1.605(3), C30-N3 1.354(3), C30-N4 1.299(3), N1-Mg1-N2 96.84(8), N1-Mg1-O1-111.57(8), N2-Mg1-O1 116.31(8), N3-Mg1-N1 127.47(9), N3-Mg1-N2 122.14(9), N3-Mg1-O1 83.10(7), N3-C30-B1 110.48(19), N4-C30-B1 126.0(2), N4-C30-N3 123.4(2). 
electrophilic carbon centre of $t-\mathrm{BuN}=\mathrm{C}=\mathrm{N} t$ - $\mathrm{Bu}$. The ligand adopts an $N, N$-chelated $\kappa^{2}$-coordination mode to magnesium, which is analogous to the previously reported derivative, compound 8. In the absence of the DMAP co-ligand, however, the magnesium centre of $\mathbf{1 1}$ is four-coordinate with the coordination environment of Mg1 completed solely by the bidentate BDI anion. Most likely a result of the lower coordination number of the magnesium centre, the $\mathrm{Mg}-\mathrm{N}$ distances to the boryl amidinate ligand of $\mathbf{1 1}$ [Mg1-N3 2.0193(17), Mg1-N4 2.0638(18) $\AA]$ are appreciably shorter than the corresponding bond lengths observed in 8 [2.1100(10), 2.2124(10) $⿱$ ] . In both compounds, however, the $\mathrm{C}-\mathrm{B}$ bond lengths are effectively identical [8: 1.5972(17); 11: 1.593(3) Å], while the relevant C-N bond lengths [8: 1.3383(14), 1.3228(15); 11: 1.344(3), 1.338(3) ̊] are indicative of a similar level of delocalisation across the amidinato chelate.

Although the basic constitution of the C-borylamidinate anions of both $\mathbf{8}$ and $\mathbf{1 1}$ is broadly reminiscent of alkyl or aryl amidinates resulting from the reaction of carbodiimides with the M-C bonds of polar $\sigma$-organometallics, ${ }^{64,65}$ the only other precedent for directly analogous C-borylamidinate formation is provided by a scandium derivative, which was itself generated by use of compound $1 .{ }^{66} \mathrm{We}$, thus, assayed the generality of the reactivity of compound 5 with a further range of readily available $N, N^{\prime}$-dialkyl and diaryl carbodiimides (Scheme 3).

As was the case for the synthesis of compound 11, reaction with $\mathrm{i}-\mathrm{PrN}=\mathrm{C}=\mathrm{N}-\mathrm{i}-\mathrm{Pr}$ required heating to $80{ }^{\circ} \mathrm{C}$ to ensure complete conversion to the borylamidinate (12). In contrast, both reactions with the $N$-aryl carbodiimides proceeded smoothly at room temperature, irrespective of the steric demands of the $N$-aryl substituent. Although the respective ${ }^{1} \mathrm{H}$ NMR spectra of the $N$-i-Pr and $N$ - $p$-tolyl borylamidinate derivatives, compounds 12 and 13, were analogous to that observed for compound $\mathbf{1 1}$ and, thus, consistent with the adoption of similar pseudo- $\mathrm{C}_{2}$ symmetric structures in solution, the high solubility of these compounds precluded the crystallisation of pure bulk samples. In contrast, addition of $\mathrm{MesN}=\mathrm{C}=\mathrm{NMes}$ to a solution of 5 resulted in the immediate deposition of needlelike single crystals of compound 14. Although the subsequent insolubility of these crystals prohibited the acquisition of meaningful NMR data, they were found to be suitable for single crystal X-ray diffraction analysis. The results of this analysis (Fig. 1b) revealed that the $N, N^{\prime}$-mesityl-C-borylamidinate adopts an unusual bidentate $\kappa^{2}$-N,O coordination mode in which the ligand binds to magnesium through one of the mesityl-bonded nitrogen atoms and a single oxygen of the pinacolate unit. As a consequence of this unsymmetrical binding mode, and in contrast to the delocalised structures adopted by compounds $\mathbf{8}$,

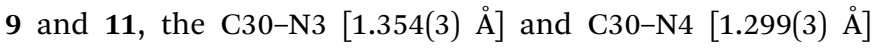
distances are consistent with localised single and double bonds, respectively. Although we have previously observed similar $\mathrm{Mg}-\mathrm{O}$ interactions between the Bpin units of a number of magnesium formamidinatoborate $[2.007(3) \AA],{ }^{58}$ formamidatoborate $[1.9631(12) \quad \AA]^{60}$ and aldimidoborate $[1.9714(11) \AA]^{59}$ derivatives, all of these compounds comprised a 4-coordinate hydridoborate as the formally charged component of the coordinated ligand. The Mg1-O1 bond length [2.1043(17) $\AA$ ] of 14, in which the appended Bpin boron centre remains three-coordinate, is consequently elongated, albeit less so than in a further closely related magnesium borylamide [(BDI)MgNDipp(Bpin)] [2.3737(18) $\AA$ ] in which the $\kappa^{2}-\mathrm{N}, \mathrm{O}$ binding is provided by a more strained 3 -membered $\mathrm{N}-\mathrm{B}-\mathrm{O}$ chelate. $^{67}$

Having confirmed its potential for B-C bond formation at the electrophilic carbon centres of carbodiimides, we turned our attention to the reactivity of compound $\mathbf{5}$ with the potentially broader substrate scope provided by $N$-alkyl and $N$-aryl imines. Initial reactions were performed between compound $\mathbf{5}$ and the $N$-alkyl aldimines, $\mathrm{N}-n$-butyl- and $N$-t-butyl-1phenylmethanimine. Assessment of both reactions after ten minutes at room temperature by ${ }^{1} \mathrm{H}$ and ${ }^{11} \mathrm{~B}\left\{{ }^{1} \mathrm{H}\right\}$ NMR spectroscopy indicated that complete consumption of $\mathbf{5}$ had again occurred with the liberation of $n$-BuBpin and the respective formation of two new $\beta$-diketiminate compounds, $\mathbf{1 5}_{\mathbf{B N}}$ and $\mathbf{1 6}_{\mathbf{B N}}$ (Scheme 4). In contrast to the data provided by compounds 11-13, however, the ${ }^{1} \mathrm{H}$ NMR spectra of compounds $15_{\mathbf{B N}}$ and $\mathbf{1 6}_{\mathbf{B N}}$ presented separate signals for all four BDI iso-propyl substituents and both BDI 'backbone' methyl environments. The latter of these resonances appeared as pairs of unique singlets at $c a$. $\delta 1.5-1.6 \mathrm{ppm}$, each with intensities corresponding to three protons by relative integration. These observations indicate that, like the starting complex $\mathbf{5}$, these species possess neither a plane of symmetry orthogonal to nor a $C_{2}$ axis in the plane of the $\beta$-diketiminate magnesium chelate. Guided by these observations and the precedent provided by the synthesis of compounds 11-14, it was anticipated that both compounds $15_{\mathbf{B N}}$ and $1 \mathbf{1 6}_{\mathbf{B N}}$ would be the amide products resulting from formal C-borylation of the electrophilic aldimine carbon centre. This expectation was refuted, however, by the definitive solid state identification provided by single crystal Xray diffraction analysis performed on both compounds after crystallisation from hexane at $-35{ }^{\circ} \mathrm{C}$. The results of these

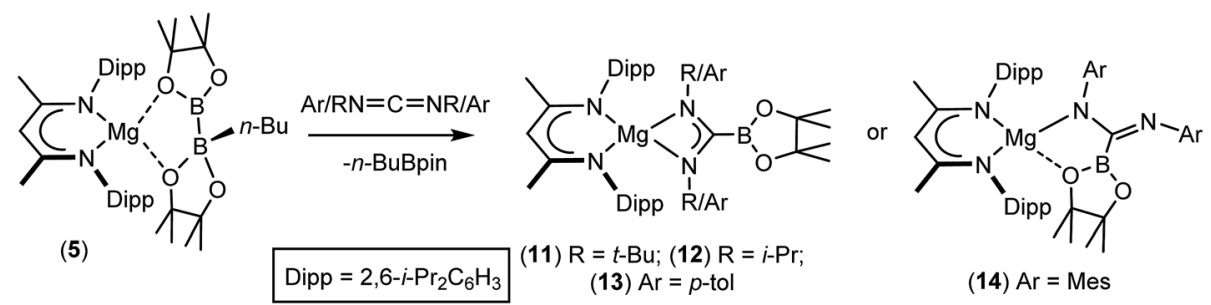

Scheme 3 Synthesis of compounds 11-14. 


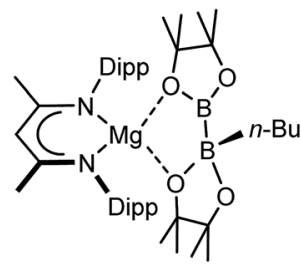

(5)

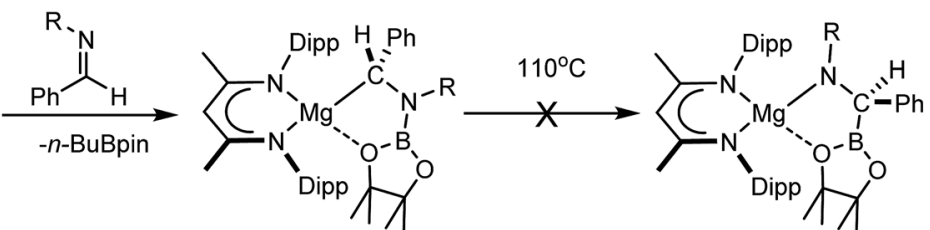

$\left(15_{\mathrm{BN}}\right) \mathrm{R}=n-\mathrm{Bu} ;\left(\Delta G_{\text {tol }}=-45.8 \mathrm{kcal} \mathrm{mol}^{-1}\right)$ $\left(16_{\mathrm{BN}}\right) \mathrm{R}=t-\mathrm{Bu} ;\left(\Delta G_{\mathrm{tol}}=-28.5 \mathrm{kcal} \mathrm{mol}^{-1}\right)$
$\left(15_{\mathrm{BC}} ; \Delta G_{\mathrm{tol}}=-39.8 \mathrm{kcal} \mathrm{mol}^{-1}\right)$

$\left(16_{\mathrm{BC}} ; \Delta G_{\mathrm{tol}}=-34.9 \mathrm{kcal} \mathrm{mol}^{-1}\right)$

Scheme 4 Synthesis of compounds $15_{\mathrm{BN}}$ and $16_{\mathrm{BN}}$ with their DFT-computed energies relative to complex 5 and those of the experimentally unobserved magnesium amide isomers, $15_{\mathrm{BC}}$ and $16_{\mathrm{BC}}$.

analyses (Fig. 2) established that both reactions had yielded an alternative regiochemistry, and the formation of aminomethylmagnesium products resulting from attachment of the boryl unit to the more electron rich nitrogen atoms of the aldimine double bonds. The compounds are, thus, denoted as $\mathbf{1 5} \mathbf{B N}$ and $16_{\mathrm{BN}}$ indicative of the $\mathrm{B}-\mathrm{N}$ bonded isomers (Scheme 4).

Despite the differing steric demands of the $N$-alkyl substituents, the structures of compounds $\mathbf{1 5}_{\mathbf{B N}}$ and $\mathbf{1 6}_{\mathbf{B N}}$ are very similar. Both compounds comprise four-coordinate magnesium centres in which the alkaline earth coordination spheres are satisfied by a bidentate BDI ligand and the relevant $N$-bor$\mathrm{yl}(\mathrm{phenyl}) \mathrm{aminomethyl} \mathrm{anions.} \mathrm{The} \mathrm{latter} \mathrm{ligands} \mathrm{are} \mathrm{bidentate}$ due to coordinative interactions from one of the pincacolato oxygen atoms of the $\mathrm{N}$-appended [Bpin] units. In both $\mathbf{1 5}_{\mathbf{B N}}$ and $\mathbf{1 6}_{\mathrm{BN}}$, the $\mathrm{Mg}-\mathrm{C}$ bond lengths [ $\left.c a .2 .16 \AA\right]$ are entirely typical of $\sigma$-bonded magnesium organometallics, while the $\mathrm{Mg}-\mathrm{O}$ bond distances $[c a .2 .15 \AA]$ are commensurate with that observed for compound $\mathbf{1 4}$ and, thus, may be judged to display similar basic characteristics to those discussed above.

The unexpected regioselectivity of this N-borylation process was investigated by density functional theory (DFT). Initial calculations performed at the BP86 level of theory (see ESI $\uparrow$ for full methodology) provided optimised geometries for $\mathbf{1 5}_{\mathbf{B N}}$ and $\mathbf{1 6}_{\mathrm{BN}}$, which corresponded closely with the experimental solid state structures and revealed the reactions of compound 5 with both $N$-alkyl aldimine substrates to be significantly exergonic (Scheme 4). Furthermore, the structure of $\mathbf{1 5}_{\mathbf{B N}}$ was computed to lie $6.0 \mathrm{kcal} \mathrm{mol}^{-1}$ lower in energy than its C-borylated isomer, the putative magnesium amide, $\mathbf{1 5}_{\mathbf{B C}}$, and these results, therefore, identify $15_{\mathbf{B N}}$ as the thermodynamic outcome of the reaction of compound 5 with the N-n-butyl aldimine substrate. In contrast, analogous calculations performed on the more sterically encumbered $N$-t-butyl species indicated isomerisation of the experimentally identified magnesium alkyl species $\left(\mathbf{1 6}_{\mathbf{B N}}\right)$ to the amide derivative $\left(\mathbf{1 6}_{\mathrm{BC}}\right)$ to be more exergonic by $-6.4 \mathrm{kcal} \mathrm{mol}^{-1}$. Despite these contrasting thermodynamic preferences, monitoring of $d_{8}$-toluene solutions of neither $\mathbf{1 5}_{\mathbf{B N}}$ nor $\mathbf{1 6}_{\mathrm{BN}}$ by ${ }^{1} \mathrm{H}$ NMR spectroscopy evidenced any observable tendency toward isomerisation to the alternative C-borylated species, even after heating at $110{ }^{\circ} \mathrm{C}$ for five days (Scheme 4).

Further reactions of compound $\mathbf{5}$ with the $\mathrm{N}$-phenyl aldimine, $\mathrm{PhN}=\mathrm{CHPh}$, and the $N$-phenyl ketimine, $\mathrm{PhN}=\mathrm{CPh}_{2}$, were monitored at room temperature by ${ }^{1} \mathrm{H}$ and ${ }^{11} \mathrm{~B}\left\{{ }^{1} \mathrm{H}\right\}$ NMR
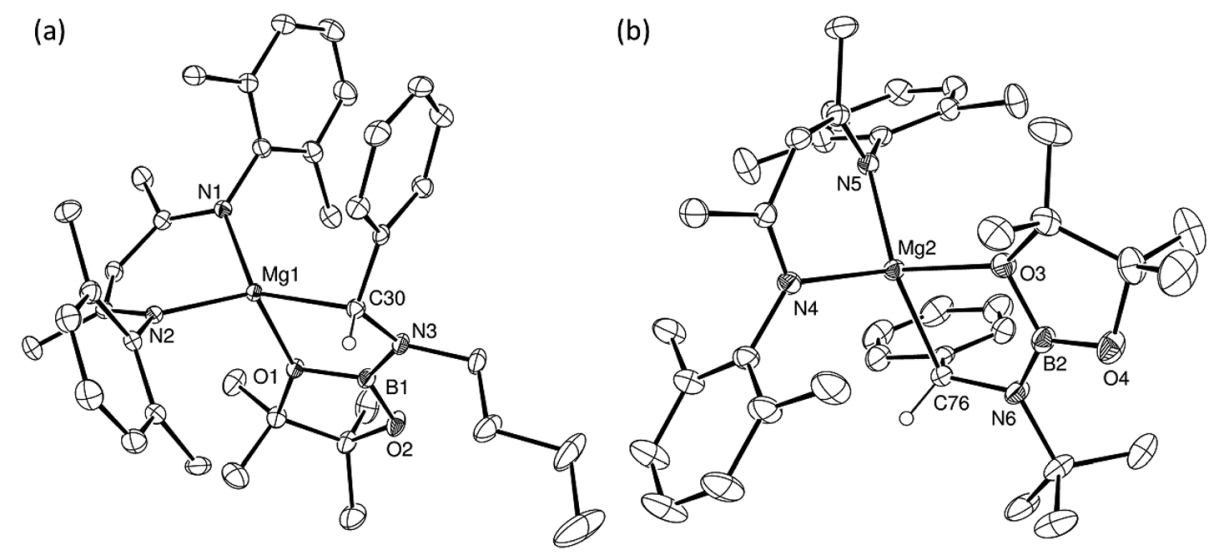

Fig. 2 ORTEP representations (25\% probability ellipsoids) of (a) compound $15_{\mathrm{BN}}$ and (b) the Mg2-containing molecule of compound $16_{\mathrm{BN}}$. Hydrogen atoms except for those attached to $\mathrm{C} 30\left(15_{\mathrm{BN}}\right)$ and $\mathrm{C} 76\left(16_{\mathrm{BN}}\right)$, iso-propyl methyl groups and the Mg1-containing molecule of compound $16_{\mathrm{BN}}$ have been removed for clarity. Selected bond lengths $(\AA)$ and angles $\left(^{\circ}\right)$ : $\left(15_{\mathrm{BN}}\right) \mathrm{Mg} 1-\mathrm{N} 12.0460(11), \mathrm{Mg} 1-\mathrm{N} 22.0301(11), \mathrm{Mg} 1-$ C30 2.1549(13), Mg1-O1 2.1250(9), N3-B1 1.3904(18), N3-C30 1.4754(16), N2-Mg1-N1 96.36(4), N2-Mg1-C30 123.40(5), N1-Mg1-O1 107.37(4), N1-Mg1-C30 129.17(5), N2-Mg1-O1 116.00(4), N2-Mg1-N1 96.36(4), N3-B1-O1 121.82(12); (16 BN) Mg2-O3 2.1061(13), Mg2-N4 2.0660(15), Mg2-N5 2.0556(15), Mg2-C76 2.1668(18), O3-B2 1.426(3), N6-C76 1.474(2), N6-B2 1.388(3), O3-Mg2-C76 82.44(6), N4-Mg2O3 118.29(6), N4-Mg2-C76 114.77(7), N6-C76-Mg2 108.67(11), N6-B2-O3 122.30(17). 
spectroscopy. In both cases, two new compounds $\left(\mathbf{1 7}_{\mathbf{B N}}\right.$ and $\mathbf{1 8}_{\mathbf{B N}}$ ) were formed in good yields (Scheme 5). Like the other aldimine-derived derivatives, $\mathbf{1 5}_{\mathbf{B N}}$ and $16_{\mathbf{B N}}$, compound $\mathbf{1 7}_{\mathbf{B N}}$ displayed ${ }^{1} \mathrm{H}$ and ${ }^{13} \mathrm{C}\left\{{ }^{1} \mathrm{H}\right\}$ NMR spectra consistent with the absence of a plane of symmetry orthogonal to the BDI chelate. In contrast, the data provided by the ketamine derivative, compound $18_{\mathbf{B N}}$, were characteristic of a symmetrically disposed diphenylmethylmagnesium species. These deductions were confirmed by single crystal X-ray diffraction analysis, which established that both compounds $\mathbf{1 7}_{\mathbf{B N}}$ and $\mathbf{1 8}_{\mathbf{B N}}$ were again the $\mathrm{N}$-borylated organomagnesium products formed through formal addition of a boryl anion to the previously unsaturated imine nitrogen centre (Fig. 3). Although there are some minor variations across the individual $\mathrm{Mg}-\mathrm{C}, \mathrm{Mg}-\mathrm{O}$ and B-N bond lengths, these measurements are within the accepted norms for single bonds of these types and necessitate no further comment.

The reactions providing both $\mathbf{1 7}_{\mathbf{B N}}$ and $\mathbf{1 8}_{\mathbf{B N}}$ from 5 were calculated to be significantly exergonic $\left(\mathbf{1 7}_{\mathbf{B N}}, \Delta G_{\text {tol }}=\right.$ $\left.-34.8 \mathrm{kcal} \mathrm{mol}^{-1} ; \mathbf{1 8}_{\mathrm{BN}}, \Delta G_{\mathrm{tol}}=-37.1 \mathrm{kcal} \mathrm{mol}^{-1}\right)$. As was the case for the $\mathrm{N}$ - $n$-butyl product, $\mathbf{1 5}_{\mathbf{B N}}$, this computational assessment indicated that $\mathbf{1 8}_{\mathbf{B N}}$ described the more stable regioisomer $\left(\mathbf{1 8}_{\mathrm{BC}}, \Delta G_{\mathrm{tol}}=-30.5 \mathrm{kcal} \mathrm{mol}^{-1}\right)$ by $6.6 \mathrm{kcal} \mathrm{mol}^{-1}$. In contrast, the aldimine reaction product, $\mathbf{1 7}_{\mathbf{B N}}$, was, like $\mathbf{1 6}_{\mathbf{B N}}$, identified as the kinetic reaction product and calculated to lie $3.6 \mathrm{kcal} \mathrm{mol}^{-1}$ higher in free energy than the corresponding Cborylated amide species, $\mathbf{1 7}_{\mathbf{B C}}$ (Scheme 5). Counter to the expectation provided by these differing outcomes, heating of both organomagnesium compounds, $\mathbf{1 7}_{\mathbf{B N}}$ and $\mathbf{1 8}_{\mathbf{B N}}$, overnight in $d_{8}$-toluene at $80{ }^{\circ} \mathrm{C}$ resulted in their clean conversion to two further new $\beta$-diketiminato magnesium derivatives, designated as compounds $\mathbf{1 7}_{\mathbf{B C}}$ and $18_{\mathbf{B P h}}$, respectively. Although compound $1_{\text {BC }}$ continued to display ${ }^{1} \mathrm{H}$ and ${ }^{13} \mathrm{C}\left\{{ }^{1} \mathrm{H}\right\}$ NMR signatures reminiscent of its precursor, compound $\mathbf{1 7}_{\mathbf{B N}}$, the apparent $\mathrm{C}_{2}$ symmetry provided to compound $1 \mathbf{1}_{\mathbf{B N}}$ by its

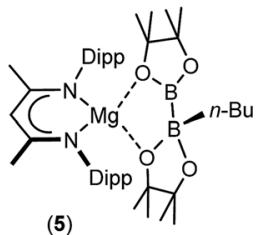

(5)

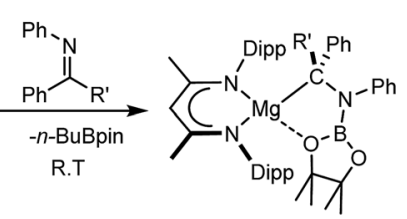

$\left(17_{\mathrm{BN}}\right) \mathrm{R}^{\prime}=\mathrm{H} \quad\left(\Delta G_{\text {tol }}=-34.8 \mathrm{kcal} \mathrm{mol}{ }^{-1}\right)$ $\left(18_{\mathrm{BN}}\right) \mathrm{R}^{\prime}=\mathrm{Ph}\left(\Delta G_{\mathrm{tol}}=-37.1 \mathrm{kcal} \mathrm{\textrm {mol } ^ { - 1 }}\right)$
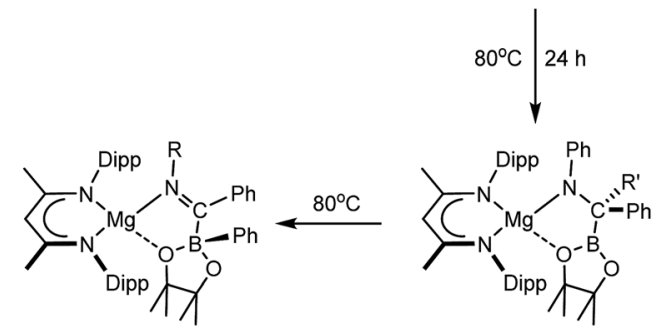

$\left(18_{\mathrm{BPh}}\right)\left(\Delta G_{\mathrm{tol}}=-36.6 \mathrm{kcal} \mathrm{mol}^{-1}\right) \quad\left(17_{\mathrm{BC}}\right) \mathrm{R}^{\prime}=\mathrm{H}\left(\Delta G_{\mathrm{tol}}=-38.4 \mathrm{kcal} \mathrm{mol}^{-1}\right)$ $\left(1_{\mathrm{BC}}\right) \mathrm{R}^{\prime}=\mathrm{Ph}$, not observed $\left(\Delta G_{\mathrm{tol}}=-30.5 \mathrm{kcal} \mathrm{mol}^{-1}\right)$

Scheme 5 Synthesis of compounds $17_{\mathrm{BN}}$ and $18_{\mathrm{BN}}$ and their isomerisation to compounds $17_{\mathrm{BC}}$ and $18_{\mathrm{BPh}}$, respectively. DFT-computed energies are given in parenthesis relative to complex 5 . diphenylmethyl anion was lost upon conversion to compound $\mathbf{1 8}_{\mathbf{B P h}}$. The origin of these observations was again resolved by isolation of samples of compounds $\mathbf{1 7}_{\mathbf{B C}}$ and $\mathbf{1 8}_{\mathbf{B P h}}$ suitable for $\mathrm{X}$-ray diffraction analysis, the results of which are illustrated in Fig. 4.

The solid-state structure of compound $\mathbf{1 7}_{\mathbf{B C}}$ confirmed its constitution as a C-borylated magnesium amide and the product of nitrogen-to-carbon transfer of the $\{$ Bpin $\}$ unit from compound $\mathbf{1 7}_{\mathbf{B N}}$. The resultant structure displayed a close correspondence to the optimised geometry of $\mathbf{1 7}_{\mathbf{B C}}$ with B1-C36

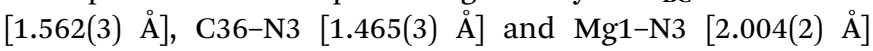
distances that are consistent with their assignment as single bonds within the normal ranges. Notably, the angle subtended by B1-C36-N3 [108.73(19) $\AA$ ] is also close to the tetrahedral value expected for this completely saturated unit. In contrast, compound $\mathbf{1 8}_{\mathbf{B P h}}$ is a further amidomagnesium isomerisation product resulting from intramolecular carbon-to-boron phenyl transfer between the previously magnesium-bound diphenylmethanide carbon centre and the boron of the $\{$ Bpin $\}$ unit (Scheme 5). The asymmetry apparent in the solution NMR analysis of compound $\mathbf{1 8}_{\mathbf{B P h}}$ is, therefore, readily ascribed to the generation of the stereogenic phenyl(pinacolato)borate unit and the resultant loss of the plane of symmetry associated with the chelated anion. The short N3-C36 [1.2967(19) ^] bond distance and the almost trigonal geometry at C36 [N3-C36-B1 $119.08(12)^{\circ} ; \Sigma($ angles subtended at C36 $\left.)=359.68^{\circ}\right]$ also indicate that the magnesium-bound $\mathrm{N}-\mathrm{C}-\mathrm{B}-\mathrm{O}$ chelate is best described as arising from coordination of an $\mathrm{N}$-phenyl-C-iminoborate. Although no magnesium compounds containing this precise type of anion appear to have been reported previously, the $\mathrm{C}-\mathrm{N}$, $\mathrm{C}-\mathrm{B}$ and $\mathrm{Mg}-\mathrm{B}$ bond lengths show reasonable correspondence with the relevant comparable distances within several organomagnesium derivatives of a tris(4,4-dimethyl-2-oxazolinyl) phenylborate spectator ligand that have been applied by Sadow and co-workers in a variety of catalytic processes. ${ }^{68-73}$

The kinetics of the transformations of compounds $17_{\mathbf{B N}}$ to $1_{\mathrm{BC}}$ and of $18_{\mathbf{B N}}$ to $18_{\mathbf{B P h}}$ were monitored by ${ }^{1} \mathrm{H}$ NMR spectroscopy over a range of temperatures $\left(60,65,70,75^{\circ} \mathrm{C}\right)$. In both systems, only the starting materials and the final products were observed throughout the reactions and no further intermediates or side products could be identified. Plots of $\ln [17]$ and $\ln$ [18] were found to be linear for $>3$ half-lives at all four temperatures of study and the resultant first order rate constants enabled the construction of Arrhenius and Eyring plots and determination of the macro- and microscopic activation parameters presented in Table 1 . Both the activation energies and enthalpies of activation are consistent with the mild thermal conditions necessary to induce both transformations. Although entropies of activation are notoriously open to interpretation, ${ }^{74}$ the negligible $\Delta S^{\neq}$values associated with both processes suggest that the gross constitutions of the starting materials are maintained and that the isomerisation reactions are intramolecular in origin.

Further insight into the formation and transformation of compounds $\mathbf{1 7}_{\mathbf{B N}}$ and $\mathbf{1 8}_{\mathbf{B N}}$ was provided by DFT (BP86) calculations, which were performed to interrogate the nature and energetics of any plausible intermediates and transition states. 
(a)

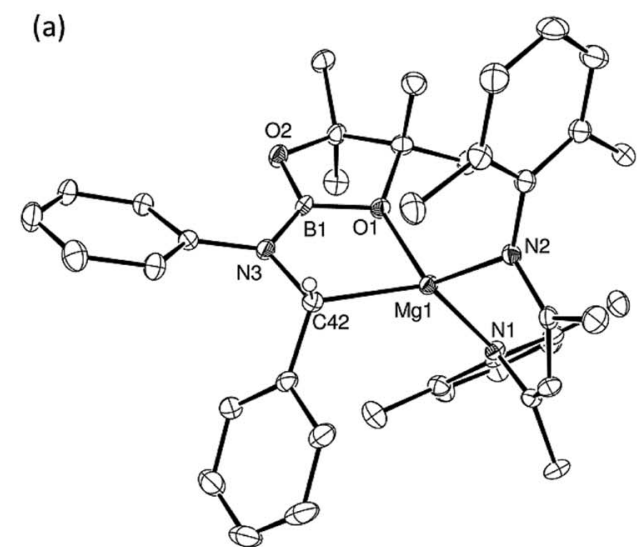

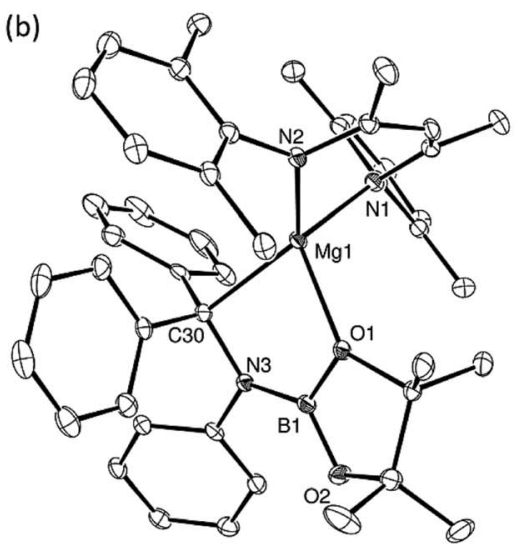

Fig. 3 ORTEP representations (25\% probability ellipsoids) of (a) compound $17_{\mathrm{BN}}$ and (b) compound $18_{\mathrm{BN}}$. Hydrogen atoms except $\mathrm{H} 42$ in $17_{\mathrm{BN}}$, iso-propyl methyl groups and occluded solvent in $18_{\mathrm{BN}}$ are removed for clarity. Selected bond lengths $(\AA)$ and angles $\left(^{\circ}\right)$ : (17 $\left.\mathrm{BN}\right) \mathrm{Mg} 1-\mathrm{O} 12.018(3)$, Mg1-N1 2.039(3), Mg1-N2 2.051(3), Mg1-C42 2.197(3), N3-C42 1.491(4), N3-B1 1.397(5), O1-Mg1-N1 113.03(12), O1-Mg1-N2 119.93(12), O1Mg1-C42 82.00(11), N1-Mg1-N2 94.59(12), N1-Mg1 C42 131.04(13), N2-Mg1-C42 118.58(13), B1-O1-Mg1 113.5(2); (18 BN) Mg1-O1 2.1188(15), Mg1-N1 2.0940(18), Mg1-N2 2.0600(17), Mg1-C30 2.2343(18), N3-C30 1.493(2), N3-B1 1.417(3), O1-Mg1-C30 80.92(6), N1-Mg1-O1 111.90(7), N1-Mg1-C30 126.79(7), N2-Mg1-O1 112.77(6), N2-Mg1-N1 95.62(7), N2-Mg1-C30 127.91(8).

Multiple attempts were made to optimise a geometry in which the less sterically encumbered imine, PhNCHPh, coordinates through its $\mathrm{C}$ or $\mathrm{N}$ atom at the $\mathrm{Mg}$ centre of 5. Irrespective of the starting orientation, however, the alkaline earth atom was found to be too crowded to allow any type of coordination due to the steric requirements of the $\mathrm{N}$ - and C-bonded phenyl groups, which hinder the direct approach of the imine to magnesium.

The NPA charges of the three- and four-coordinate boron centres of the $[\operatorname{pinBBpin}(n \mathrm{Bu})]^{-}$ligand of 5 provided results reminiscent of those described by Bo, Fernandez and coworkers for the $[\operatorname{pinBBpin}(\mathrm{OMe})]^{-}$anion. ${ }^{39}$ The threecoordinate boron of the $\{$ Bpin\} unit was found to manifest a substantial positive charge $(+0.848)$, which, although less positive than the charge borne by the sterically encumbered magnesium centre (+1.578), is significantly more electron rich
$(+0.582)$ than the four-coordinate boron atom of the $\{\operatorname{pinB}(n-$ $\mathrm{Bu})\}$ component of the diboranate complex anion. These observations militate against the reactivity of compound 5 as a source of nucleophilic [Bpin] $]^{-}$and not only infer that the coordinatively unsaturated BBpin\} unit displays considerable electrophilic potential but also that the B-B bond is significantly polarised toward the higher coordinate boron centre. Prompted by these observations, an alternative 'outer sphere' diboranate activation process invoking nucleophilic imine addition at the three-coordinate boron atom was assessed.

Fig. 5 illustrates the resultant free energy profile for the reaction of 5 with $\mathrm{PhN}=\mathrm{CHPh}$ and the subsequent isomerisation of $17_{\mathbf{B N}}$ to $17_{\mathbf{B C}}$. The formation of the $\mathrm{B}-\mathrm{N}$ bond of $17_{\mathbf{B N}}$ is initiated by attack of the imine nitrogen at the threecoordinate boron centre of the diboranate anion of $\mathbf{5}$. The (a)

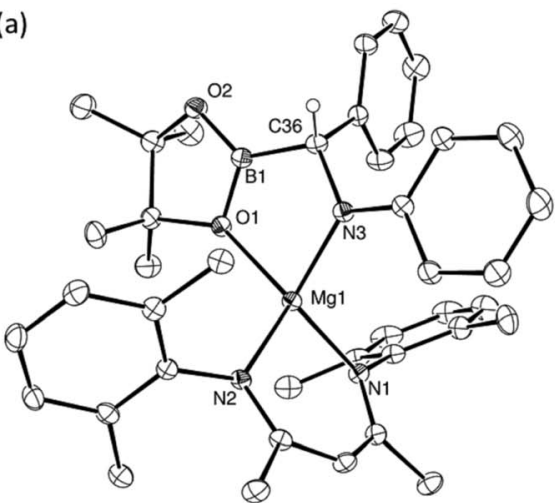

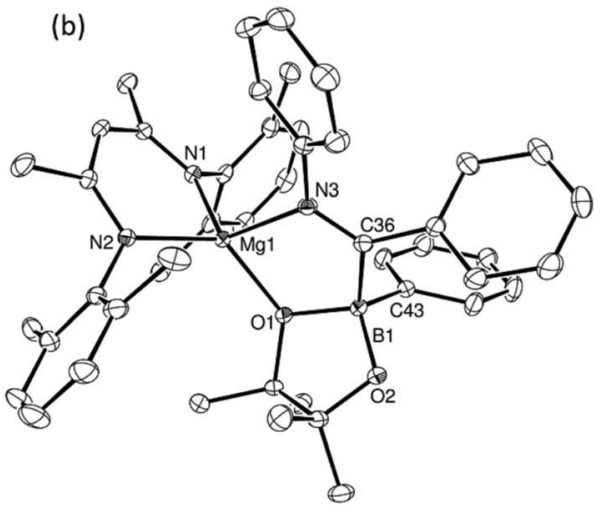

Fig. 4 ORTEP representations (25\% probability ellipsoids) of (a) compound $17_{\mathrm{BC}}$ and (b) compound $18_{\mathrm{BPh}}$. Hydrogen atoms except $\mathrm{H} 36$ in $17_{\mathrm{BC}}$ and iso-propyl methyl groups are removed for clarity. Selected bond lengths ( $(\AA)$ and angles $\left({ }^{\circ}\right)$ : (17 $\left.{ }_{B C}\right)$ Mg1-O1 2.1679(18), Mg1-N1 2.072(2), Mg1-N2 2.0615(19), Mg1-N3 2.004(2), O1-B1 1.397(3), N3-C36 1.465(3), C36-B1 1.562(3), N1-Mg1-O1 129.95(8), N2-Mg1-O1 114.67(8), N2Mg1-N1 93.78(8), N3-Mg1-O1 83.59(8), N3-Mg1-N1 113.24(9), N3-Mg1-N2 125.52(8), N3-C36-B1 108.73(19); (18 Mg1-N1 2.0612(12), Mg1-N2 2.0649(12), Mg1-N3 2.1218(12), O1-B1 1.5343(17), N3-C36 1.2967(19), C36-B1 1.6505(19), C43-B1 1.621(2), O1Mg1-N1 120.14(5), O1-Mg1-N2 131.08(5), O1-Mg1-N3 83.93(4), N1-Mg1-N2 93.18(5), N1-Mg1-N3 116.63(5), N2-Mg1-N3 113.76(5), C36N3-Mg1 113.37(9), N3-C36-B1 119.08(12), C43-B1-C36 108.28(11), O1-B1-C36 106.72(11), B1-O1-Mg1 115.32(8). 
Table 1 Kinetic activation parameters for the isomerisation of compounds $17_{\mathrm{BN}}$ and $18_{\mathrm{BN}}$ to $17_{\mathrm{BC}}$ and $18_{\mathrm{BPh}}$, respectively

\begin{tabular}{llll}
\hline & $\begin{array}{l}E_{\mathrm{a}} \\
\left(\mathrm{kcal} \mathrm{mol}^{-1}\right)\end{array}$ & $\begin{array}{l}\Delta H^{\neq} \\
\left(\mathrm{kcal} \mathrm{mol}^{-1}\right)\end{array}$ & $\begin{array}{l}\Delta S^{\neq} \\
\left(\mathrm{cal} \mathrm{K}^{-1} \mathrm{~mol}^{-1}\right)\end{array}$ \\
\hline $\mathbf{1 7}_{\mathbf{B N}} \rightarrow \mathbf{1 7}_{\mathbf{B C}}$ & $22.3(0.2)$ & $21.6(0.2)$ & $-0.01(0.6)$ \\
$\mathbf{1 8}_{\mathbf{B N}} \rightarrow \mathbf{1 8}_{\mathbf{B P h}}$ & $25.3(0.3)$ & $24.7(0.3)$ & $-0.001(1.0)$
\end{tabular}

formation of compound $\mathbf{1 7}_{\mathbf{B N}}$ ensues through assembly of an adduct species, [INT(5-17 $\mathbf{B N})$ ], which is $3.7 \mathrm{kcal} \mathrm{mol}^{-1}$ higher in energy than the adduct, $\mathbf{5} \cdot \mathrm{PhNCHPh}$. Consistent with the effectively spontaneous generation of $\mathbf{1 7}_{\mathbf{B N}}$, however, accomplishment of this significantly exergonic transformation $\left(\Delta G_{\text {tol }}\right.$ $=-34.8 \mathrm{kcal} \mathrm{mol}{ }^{-1}$ ) necessitates the traversal of two very

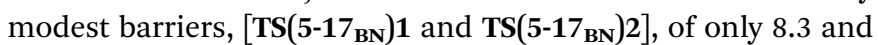
$6.7 \mathrm{kcal} \mathrm{mol}^{-1}$, respectively. This process occurs within the magnesium coordination sphere to effect the cleavage of the $\mathrm{B}-\mathrm{B}$ bond of the diboranate unit, which is observed to elongate from $1.83 \AA$ [INT(5-17 $\left.\left.{ }_{\mathbf{B N}}\right)\right]$ to $2.44 \AA$ at $\mathbf{T S}\left(5-17_{\mathbf{B N}}\right) 2$ (Fig. 6a) en route to its complete rupture and the formation of $\mathbf{1 7}_{\mathbf{B N}}$. Indicative of the necessary redistribution of electron density, the calculated charges of the now four-coordinate nitrogen- and carbon-bound boron centres $(+1.078$ and +1.024 , respectively)

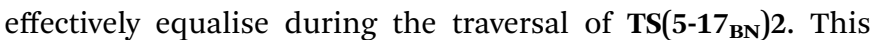
transformation, therefore, may be viewed as an obverse $\mathrm{S}_{\mathrm{N}} 2$ process resulting in the displacement of the $n$ BuBpin component of the diboronate anion by the similarly neutral aldimine substrate. From this perspective, the addition of the [Bpin $]^{-}$ anion to the reducible aldimine is best rationalised as a consequence of the electrophilic character of this three-coordinate boron centre rather than any intrinsic nucleophilicity associated with the $\mathrm{B}-\mathrm{B}$ bond of the $[\operatorname{pinBB}(n-\mathrm{Bu}) \operatorname{pin}]^{-}$anion.

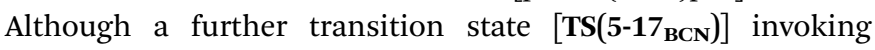
effective attack of the aldimine $\mathrm{sp}^{2}$ carbon on the electrophilic boron centre of $\mathbf{5}$ was also located, this was very much higher in energy ( $30.3 \mathrm{kcal} \mathrm{mol}^{-1}$ ) and ultimately led to the C-borylated magnesium amide, $\mathbf{1 7}_{\mathbf{B C}}$ (via $\mathbf{1 7}_{\mathbf{B C N}}$, vide infra), rather than the experimentally observed organomagnesium derivative $\left(\mathbf{1 7}_{\mathbf{B N}}\right)$ (Fig. 5).

In correspondence with the thermal conditions necessary for the observation of the reaction, an activation barrier of some $26.2 \mathrm{kcal} \mathrm{mol}^{-1}\left[\mathrm{TS}\left(\mathbf{1 7}_{\mathbf{B N}}-\mathbf{1 7}_{\mathbf{B C N}}\right)\right]$ must be overcome to induce the isomerisation of $\mathbf{1 7}_{\mathbf{B N}}$ to the amidomagnesium derivative, $\mathbf{1 7}_{\mathbf{B C}}$. Consistent with the negligible entropy of activation deduced for this transformation (Table 1), the transferral of the \{Bpin\} unit between nitrogen and carbon is purely intramolecular in origin. This process invokes the intermediacy of the azaboranuidacyclopropane species, $\mathbf{1 7}_{\mathbf{B C N}}$ (Fig. $\mathbf{6 b}$ ), which is generated by the breaking of the aminobenzyl C-Mg bond of $\mathbf{1 7}_{\mathbf{B N}}$. Although $\mathbf{1 7}_{\mathbf{B C N}}$ is stabilised by a significant interaction between the magnesium centre and one of the pinacolato oxygen atoms $(2.08 \AA)$, it is unobservable under the experimental conditions and, most likely as a result of its inherent ring strain, is transformed immediately to $17_{\mathbf{B C}}$ via a negligible barrier $\left[\mathrm{TS}\left(\mathbf{1 7}_{\mathrm{BCN}^{-1}} \mathbf{1}_{\mathrm{BC}}\right)\right]$ of $4.1 \mathrm{kcal} \mathrm{mol}^{-1}$. Although a related

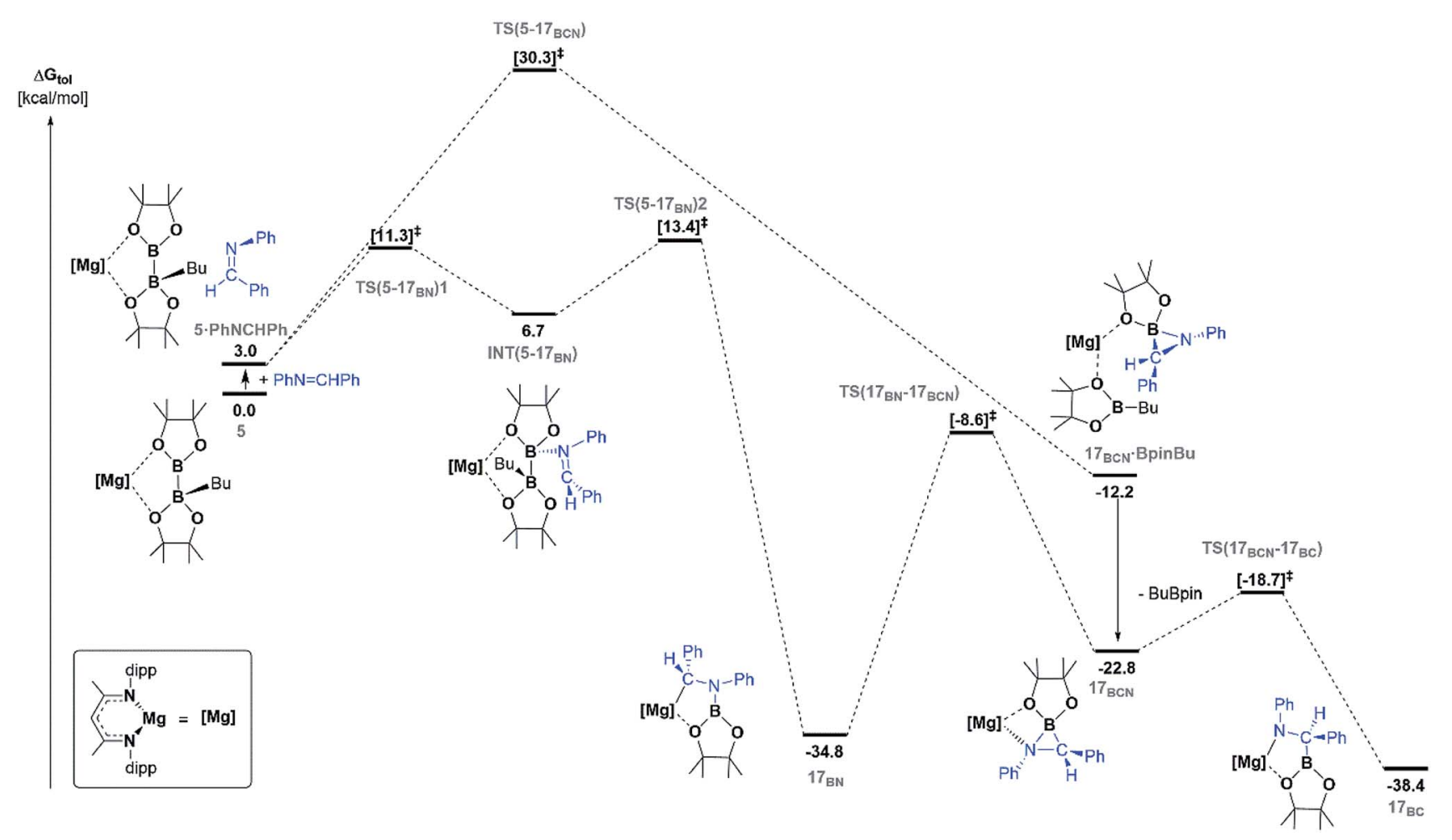

Fig. 5 DFT calculated free energy $\left(\mathrm{kcal} \mathrm{mol}^{-1}\right)$ profile for the reaction of $\mathrm{PhN}=\mathrm{CHPh}$ with compound 5 (in toluene), relative to 5 and the free substrates. 
(a)

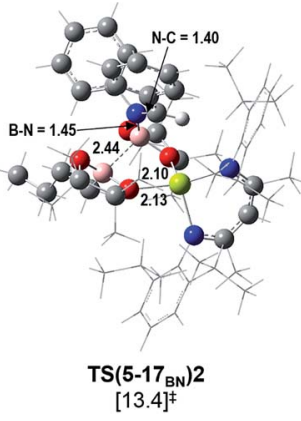

(b)

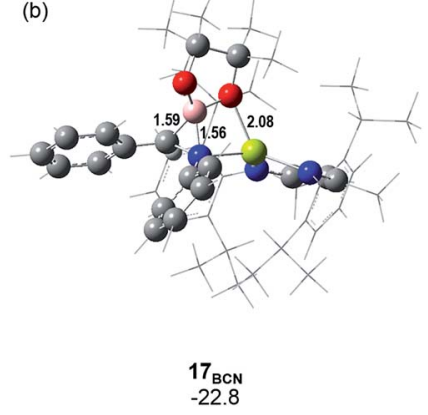

Fig. 6 The DFT calculated (a) transition state associated with B-B bond cleavage during the transformation of compound 5 to compound $17_{\mathrm{BN}} ;(\mathrm{b})$ intermediate structure of $17_{\mathrm{BCN}}$ (grey $=\mathrm{C}$; red $=$ $\mathrm{O}$; pink $=\mathrm{B}$; blue $=\mathrm{N}$; yellow $=\mathrm{Mg}$ )

nitrogen-to-carbon rearrangement has been implicated in the decomposition of $\mathrm{PhCH}_{2} \mathrm{CH}(\mathrm{Bpin})\left(\mathrm{NH}_{2}\right)$ to $\mathrm{PhCH}_{2} \mathrm{CH}_{2}-$ NHBpin, ${ }^{75}$ to the best of our knowledge, the transformation of $\mathbf{1 7}_{\mathbf{B N}}$ to $\mathbf{1 7}_{\mathbf{B C}}$ provides the first documented example of a retro aza-bora-Brook rearrangement. ${ }^{76,77}$

The isomerisation of the diphenylmethanide derivative, compound $\mathbf{1 8}_{\mathbf{B N}}$, to the borate derivative, $\mathbf{1 8}_{\mathbf{P h}}$, (Scheme 5) was also examined computationally (Fig. S38†). Consistent with the experimental analysis summarised in Table 1 , a rate determining kinetic barrier $\left[\mathbf{T S}\left(\mathbf{1 8}_{\mathrm{BN}}-\mathbf{1 8}_{\mathrm{BCN}}\right)\right]$ of $21.6 \mathrm{kcal} \mathrm{mol}^{-1}$ must be surmounted during an initial intramolecular isomerisation step to an azaboranuidacyclopropane species, $\mathbf{1 8}_{\mathbf{B C N}}$. This species is analogous to $\mathbf{1 7}_{\mathbf{B C N}}$ (Fig. $6 \mathrm{~b}$ ) and is similarly labile with respect to its onward transformation to a putative amide derivative, $\mathbf{1 8}_{\mathbf{B C}}$. In contrast to the greater thermodynamic viability deduced of compound $\mathbf{1 7}_{\mathrm{BC}}$ over $\mathbf{1 7}_{\mathrm{BN}}$, compound $\mathbf{1 8}_{\mathrm{BC}}$ was found to lie marginally higher $\left(6.6 \mathrm{kcal} \mathrm{mol}^{-1}\right)$ in energy than its isolable organomagnesium isomer, $\mathbf{1 8}_{\mathbf{B N}}$. While we suggest that this is a likely consequence of the enhanced benzhydrylic stabilization of the $\mathrm{Mg}-\mathrm{C}$ interaction, any generation of $\mathbf{1 8}_{\mathbf{B C}}$ will be fleeting with respect to the formation of the ultimate, and experimentally confirmed, reaction product, $\mathbf{1 8}_{\mathbf{P h}}$, which effects carbon-to-boron phenyl migration via $\mathbf{T S}\left(\mathbf{1 8}_{\mathbf{B C}^{-}}\right.$ $\mathbf{1 8}_{\mathrm{BPh}}$ ) with a barrier of $19.4 \mathrm{kcal} \mathrm{mol}^{-1}$.

\section{Conclusion}

The results described herein confirm that a magnesium diboranate complex (5) derived from commercially available $\mathrm{B}_{2} \operatorname{pin}_{2}$ can, like previously reported desymmetrised diborane esters, act as an apparent source of an anionic boryl nucleophile. Consistent with the transference of a [Bpin $]^{-}$anion displaying significant nucleophilic character, reactions with carbodiimides result in the formation of C-borylamidinate species as the only magnesium-containing reaction products. Treatment of compound $\mathbf{5}$ with a variety of $N$-alkyl or aryl aldimine or ketimine substrates, however, provided consistent access to N-borylated organomagnesium compounds. In these cases, the B-B bond breaking event is initiated by displacement of charge neutral $n$-BuBpin through an approach of the imine nitrogen atom to the three-coordinate $\{$ Bpin $\}$ component of the diboranate anion. This process enables production of a boronnitrogen bonded isomer not only when the magnesium organometallic is thermodynamically more stable but also when the alternate C-bonded magnesium amide isomer is lower in free energy. In such instances, the $\mathrm{N}$-boron bonded kinetic reaction products can be isolated but may be converted to their thermodynamically more stable isomers via an accessible intramolecular pathway. While more direct nucleophilic attack at magnesium cannot be discounted for less sterically encumbered bases, and we do not suggest that this mode of heterolytic activation is operant in all instances when diborane desymmetrisation results in generation of boryl anion equivalents, our results suggest that this outer sphere mechanism is a viable route for consideration. We are continuing to study the implications of these observations, particularly with regard to the rational design of further reactive alkaline earth and group 13centred systems.

\section{Conflicts of interest}

There are no conflicts of interest to declare.

\section{Acknowledgements}

The authors would like to thank the Engineering and Physical Sciences Research Council (UK) for their generous support of this research (Grants: EP/N014456/1 and EP/R020752/1). This research made use of the Balena High Performance Computing (HPC) Service at the University of Bath.

\section{References}

1 M. Wagner, N. Hommes, H. Noth and P. V. Schleyer, Inorg. Chem., 1995, 34, 607-614.

2 Y. Segawa, M. Yamashita and K. Nozaki, Science, 2006, 314, 113-115.

3 T. B. Marder, Science, 2006, 314, 69-70.

4 Y. Segawa, Y. Suzuki, M. Yamashita and K. Nozaki, J. Am. Chem. Soc., 2008, 130, 16069-16079.

5 M. Yamashita and K. Nozaki, in Synthesis and Application of Organoboron Compounds, ed. E. Fernandez and A. Whiting, 2015, vol. 49, pp. 1-37.

6 H. Braunschweig, Angew. Chem., Int. Ed., 2007, 46, 19461948.

7 M. Yamashita, Y. Suzuki, Y. Segawa and K. Nozaki, J. Am. Chem. Soc., 2007, 129, 9570-9571.

8 Y. Segawa, M. Yamashita and K. Nozaki, Angew. Chem., Int. Ed., 2007, 46, 6710-6713.

9 T. Terabayashi, T. Kajiwara, M. Yamashita and K. Nozaki, J. Am. Chem. Soc., 2009, 131, 14162-14163.

10 T. Arnold, H. Braunschweig, W. C. Ewing, T. Kramer, J. Mies and J. K. Schuster, Chem. Commun., 2015, 51, 737-740.

11 A. V. Protchenko, K. H. Birjkumar, D. Dange, A. D. Schwarz, D. Vidovic, C. Jones, N. Kaltsoyannis, P. Mountford and S. Aldridge, J. Am. Chem. Soc., 2012, 134, 6500-6503. 
12 A. V. Protchenko, D. Dange, J. R. Harmer, C. Y. Tang, A. D. Schwarz, M. J. Kelly, N. Phillips, R. Tirfoin, K. H. Birjkumar, C. Jones, N. Kaltsoyannis, P. Mountford and S. Aldridge, Nat. Chem., 2014, 6, 315-319.

13 D. Dange, A. Davey, J. A. B. Abdalla, S. Aldridge and C. Jones, Chem. Commun., 2015, 51, 7128-7131.

14 J. Campos and S. Aldridge, Angew. Chem., Int. Ed., 2015, 54, 14159-14163.

15 R. Frank, J. Howell, J. Campos, R. Tirfoin, N. Phillips, S. Zahn, D. M. P. Mingos and S. Aldridge, Angew. Chem., Int. Ed., 2015, 54, 9586-9590.

16 Y. Okuno, M. Yamashita and K. Nozaki, Angew. Chem., Int. Ed., 2011, 50, 920-923.

17 B. L. Wang, Y. X. Li, R. Ganguly, H. Hirao and R. Kinjo, Nat. Commun., 2016, 7, 11871.

18 W. Lu, H. T. Hu, Y. X. Li, R. Ganguly and R. Kinjo, J. Am. Chem. Soc., 2016, 138, 6650-6661.

19 H. Braunschweig, C. W. Chiu, K. Radacki and T. Kupfer, Angew. Chem., Int. Ed., 2010, 49, 2041-2044.

20 H. Braunschweig, M. Burzler, R. D. Dewhurst and K. Radacki, Angew. Chem., Int. Ed., 2008, 47, 5650-5653.

21 H. Braunschweig, R. D. Dewhurst, L. Pentecost, K. Radacki, A. Vargas and Q. Ye, Angew. Chem., Int. Ed., 2016, 55, 436440.

22 R. Kinjo, B. Donnadieu, M. A. Celik, G. Frenking and G. Bertrand, Science, 2011, 333, 610-613.

23 D. A. Ruiz, M. Melaimi and G. Bertrand, Chem. Commun., 2014, 50, 7837-7839.

24 L. B. Kong, Y. X. Li, R. Ganguly, D. Vidovic and R. Kinjo, Angew. Chem., Int. Ed., 2014, 53, 9280-9283.

25 L. B. Kong, R. Ganguly, Y. X. Li and R. Kinjo, Chem. Sci., 2015, 6, 2893-2902.

26 D. Wu, L. B. Kong, Y. X. Li, R. Ganguly and R. Kinjo, Nat. Commun., 2015, 6, 7340.

27 T. Imamoto and T. Hikosaka, J. Org. Chem., 1994, 59, 67536759.

28 L. B. Kong, W. Lu, Y. X. Li, R. Ganguly and R. Kinjo, Inorg. Chem., 2017, 56, 5586-5593.

29 J. Monot, A. Solovyev, H. Bonin-Dubarle, E. Derat, D. P. Curran, M. Robert, L. Fensterbank, M. Malacria and E. Lacote, Angew. Chem., Int. Ed., 2010, 49, 9166-9169.

30 D. A. Ruiz, G. Ung, M. Melaimi and G. Bertrand, Angew. Chem., Int. Ed., 2013, 52, 7590-7592.

31 E. Bernhardt, V. Bernhardt-Pitchougina, H. Willner and N. Ignatiev, Angew. Chem., Int. Ed., 2011, 50, 12085-12088.

32 J. Landmann, J. A. P. Sprenger, R. Bertermann, N. Ignat'ev, V. Bernhardt-Pitchougina, E. Bernhardt, H. Willner and M. Finze, Chem. Commun., 2015, 51, 4989-4992.

33 J. Landmann, P. T. Hennig, N. V. Ignat'ev and M. Finze, Chem. Sci., 2017, 8, 5962-5968.

34 J. Landmann, F. Keppner, D. B. Hofmann, J. A. P. Sprenger, M. Haring, S. H. Zottnick, K. Muller-Buschbaum, N. V. Ignat'ev and M. Finze, Angew. Chem., Int. Ed., 2017, 56, 2795-2799.

35 H. Ito, H. Yamanaka, J. Tateiwa and A. Hosomi, Tetrahedron Lett., 2000, 41, 6821-6825.
36 C. Kleeberg, L. Dang, Z. Y. Lin and T. B. Marder, Angew. Chem., Int. Ed., 2009, 48, 5350-5354.

37 M. Gao, S. B. Thorpe and W. L. Santos, Org. Lett., 2009, 11, 3478-3481.

38 K. S. Lee, A. R. Zhugralin and A. H. Hoveyda, J. Am. Chem. Soc., 2009, 131, 7253-7254.

39 A. Bonet, C. Pubill-Ulldemolins, C. Bo, H. Gulyas and E. Fernandez, Angew. Chem., Int. Ed., 2011, 50, 7158-7161.

40 M. Gao, S. B. Thorpe, C. Kleeberg, C. Slebodnick, T. B. Marder and W. L. Santos, J. Org. Chem., 2011, 76, 3997-4007.

41 S. B. Thorpe, X. Guo and W. L. Santos, Chem. Commun., 2011, 47, 424-426.

42 H. Gulyas, A. Bonet, C. Pubill-Ulldemolins, C. Sole, J. Cid and E. Fernandez, Pure Appl. Chem., 2012, 84, 2219-2231.

43 J. Cid, H. Gulyas, J. J. Carbo and E. Fernandez, Chem. Soc. Rev., 2012, 41, 3558-3570.

44 N. Miralles, J. Cid, A. B. Cuenca, J. J. Carbo and E. Fernandez, Chem. Commun., 2015, 51, 1693-1696.

45 S. Pietsch, E. C. Neeve, D. C. Apperley, R. Bertermann, F. Y. Mo, D. Qiu, M. S. Cheung, L. Dang, J. B. Wang, U. Radius, Z. Y. Lin, C. Kleeberg and T. B. Marder, Chem.Eur. J., 2015, 21, 7082-7098.

46 R. D. Dewhurst, E. C. Neeve, H. Braunschweig and T. B. Marder, Chem. Commun., 2015, 51, 9594-9607.

47 E. C. Neeve, S. J. Geier, I. A. I. Mkhalid, S. A. Westcott and T. B. Marder, Chem. Rev., 2016, 116, 9091-9161.

48 J. H. Zheng, Z. H. Li and H. D. Wang, Chem. Sci., 2018, 9, 1433-1438.

49 J. Cid, A. Hermann, J. E. Radcliffe, L. D. Curless, H. Braunschweig and M. J. Ingleson, Organometallics, 2018, 37, 1992-1998.

50 A. B. Cuenca, R. Shishido, H. Ito and E. Fernandez, Chem. Soc. Rev., 2017, 46, 415-430.

51 L. Garcia, J. Sendra, N. Miralles, E. Reyes, J. J. Carbo, J. L. Vicario and E. Fernandez, Chem.-Eur. J., 2018, 24, 14059-14063.

52 N. Miralles, R. Alam, K. J. Szabo and E. Fernandez, Angew. Chem., Int. Ed., 2016, 55, 4303-4307.

53 C. Pubill-Ulldemolins, A. Bonet, C. Bo, H. Gulyas and E. Fernandez, Chem.-Eur. J., 2012, 18, 1121-1126.

54 F. Haeffner, Comput. Theor. Chem., 2018, 1131, 90-98.

55 A. F. Pecharman, A. L. Colebatch, M. S. Hill, C. L. McMullin, M. F. Mahon and C. Weetman, Nat. Commun., 2017, 8, 15022.

56 A.-F. Pécharman, M. S. Hill and M. F. Mahon, Dalton Trans., 2018, 47, 6 .

57 M. S. Hill, D. J. Liptrot and C. Weetman, Chem. Soc. Rev., 2016, 45, 972-988.

58 C. Weetman, M. S. Hill and M. F. Mahon, Chem.-Eur. J., 2016, 22, 7158-7162.

59 C. Weetman, M. D. Anker, M. Arrowsmith, M. S. Hill, G. Kociok-Kohn, D. J. Liptrot and M. F. Mahon, Chem. Sci., 2016, 7, 628-641.

60 Y. Yang, M. D. Anker, J. Fang, M. F. Mahon, L. Maron, C. Weetman and M. S. Hill, Chem. Sci., 2017, 8, 3529-3537. 
61 A. F. Pecharman, M. S. Hill, C. L. McMullin and M. F. Mahon, Angew. Chem., Int. Ed., 2017, 56, 16363-16366. 62 A.-F. Pécharman, M. S. Hill, C. L. McMullin and M. F. Mahon, Organometallics, 2018, 37, 4457-4464.

63 A. F. Pecharman, M. S. Hill and M. F. Mahon, Angew. Chem., Int. Ed., 2018, 57, 10688-10691.

64 F. T. Edelmann, Chem. Soc. Rev., 2012, 41, 7657-7672.

65 F. T. Edelmann, in Adv. Organometal. Chem., ed. A. F. Hill and M. J. Fink, 2013, vol. 61, pp. 55-374.

66 S. H. Li, J. H. Cheng, Y. H. Chen, M. Nishiura and Z. M. Hou, Angew. Chem., Int. Ed., 2011, 50, 6360-6363.

67 D. J. Liptrot, M. S. Hill, M. F. Mahon and A. S. S. Wilson, Angew. Chem., Int. Ed., 2015, 54, 13362-13365.

68 J. F. Dunne, D. B. Fulton, A. Ellern and A. D. Sadow, J. Am. Chem. Soc., 2010, 132, 17680-17683.

69 S. R. Neal, A. Ellern and A. D. Sadow, J. Organomet. Chem., 2011, 696, 228-234.

70 J. F. Dunne, S. R. Neal, J. Engelkemier, A. Ellern and A. D. Sadow, J. Am. Chem. Soc., 2011, 133, 16782-16785.
71 D. Mukherjee, N. L. Lampland, K. K. Yan, J. F. Dunne, A. Ellern and A. D. Sadow, Chem. Commun., 2013, 49, 4334-4336.

72 D. Mukherjee, A. Ellern and A. D. Sadow, Chem. Sci., 2014, 5, 959-964.

73 N. L. Lampland, A. Pindwal, S. R. Neal, S. Schlauderaff, A. Ellern and A. D. Sadow, Chem. Sci., 2015, 6, 6901-6907.

74 R. Sanjeev, D. A. Padmavathi and V. Jagannadham, World J. Chem. Educ., 2018, 6, 78-81.

75 D. S. Matteson and K. M. Sadhu, Organometallics, 1984, 3, 614-618.

76 For an authenticated example of a bora-Brook rearrangement involving carbon-to-oxygen migration of a boryl group, see; H. Kisu, H. Sakaino, F. Ito, M. Yamashita and K. Nozaki, J. Am. Chem. Soc., 2016, 138, 3548-3552.

77 For a very recent observation of 1,2-boryl carbon-to-nitrogen migration, see; Z. Li, L. Zhang, M. Nishiura and Z. Hou, ACS Catal., 2019, 9, 4388-4393. 